\title{
Main results of the Korea National Hospital Discharge In-depth Injury Survey, 2004-2016
}

\author{
Sung Ok Hong' ', Boae Kim², Joongho Jo'1, Yunhyung Kwon'1, Yeon-Kyeng Lee', Youngtaek Kim³ \\ 'Division of Chronic Disease Control, Korea Centers for Disease Control and Prevention, Cheongju, Korea; ${ }^{2}$ Occupational Health Research \\ Department, Korea Occupational Safety and Health Agency, Ulsan, Korea; ${ }^{3}$ Public Health and Medical Service Office, Chungnam National \\ University Hospital, Daejeon, Korea
}

OBJECTIVES: The purpose of this study was to estimate the incidence of injuries and to identify their causes by classifying injuries according to various categories including age, sex, mechanism of injury, body parts injured, and place of injury.

METHODS: This study used data from the Korea National Hospital Discharge In-depth Injury Survey (KNHDIS) from 2004 to 2016. The KNHDIS is conducted annually by the Korea Centers for Disease Control and Prevention, and its survey population includes all hospitalized patients discharged from medical institutions that have 100 or more beds, such as hospitals, general hospitals, and secondary community health centers. The number of injured cases is weighted and estimated using the mid-year estimated population of each year.

RESULTS: The injury discharge rate steadily increased since 2004 (1,505 per 100,000 population in 2004, 2,007 per 100,000 population in 2016) and most injuries were unintentional (annual average of 94.7\%). On average, during the 13-year study period, the injury rate for males was 1.5 times as high as for females. The 2 main causes of injury were consistently traffic accidents and falls. Notably, the rate of injuries resulting from falls rose by 1.7-fold from 463 to 792 per 100,000 people, and exceeded the rate of traffic accidents in 2016.

CONCLUSIONS: The incidence of injuries steadily increased after the survey was first conducted, whereas mortality resulting from injuries mostly remained unchanged. This suggests that effective strategies and interventions should be reinforced to reduce unintentional injuries.

KEY WORDS: Injury, Hospitalization, Discharge, Surveillance, Korea

\section{INTRODUCTION}

An injury is defined as intentional or unintentional physical and/or psychological damage resulting from an external cause,

\section{Correspondence: Youngtaek Kim}

Public Health and Medical Service Office, Chungnam National University Hospital, 282 Munhwa-ro, Jung-gu, Daejeon 35015, Korea

E-mail: ruyoung01@cnuh.co.kr

Received: Feb 10, 2020 / Accepted: Jun 20, 2020 / Published: Jun 20, 2020

This article is available from: https://e-epih.org/

(c) This is an open-access article distributed under the terms of the Creative Commons Attribution License (https://creativecommons.org/licenses/by/4.0/), which permits unrestricted use, distribution, and reproduction in any medium, provided the original work is properly cited.

(C) 2020 , Korean Society of Epidemiology including conditions such as trauma and poisoning [1]. The World Health Organization classifies injuries as a non-communicable disease (a category that also includes chronic diseases) because injuries follow a chronic course until a previously normal status is restored and often result in residual psychological or biological sequelae. Injuries occur in various circumstances such as violence in schools, industrial disasters, road accidents, agricultural accidents, and accidents at festivals. Injuries are handled by diverse social safety sectors depending on where they occur and whether they are intentional; therefore, there is a need to unify dispersed data to obtain a holistic overview of the epidemiology of injuries.

Korea is ranked as one of the top countries with regard to mortality resulting from injuries [2]. The situations regarding traffic accidents involving children and mortality from industrial accidents were similar to each other, and even though Korea’s safetyrelated indices greatly improved after it joined the Organization 
for Economic Cooperation and Development (OECD), it still failed to reach OECD standards [3,4].

An analysis of injury-related disease codes in 2016 revealed that the direct health expenditures on injuries covered by national health insurance amounted to 4.0 trillion Korean won (KRW; 2.2 trillion KRW on admissions, 1.8 trillion KRW on outpatients) which accounted for $10 \%$ of all medical costs. This reflected a 3 -fold increase in injury-related health expenditures since 2004, when expenditures on injuries totaled 1.4 trillion KRW ( 0.7 trillion KRW on admissions, 0.7 trillion KRW on outpatients) [5].

The social cost due to road accidents, one of the major causes of unintentional injuries, was 26.6 trillion KRW (1.9\% of gross domestic product [GDP]) in 2014 [6]. This was a 9.5\% increase from the 24.0 trillion KRW spent in 2013 and approximately triple the 9.7 trillion KRW (1.1\% of GDP) spent in $2006[7,8]$. The loss of working days due to industrial disasters in 2016 was 47,040, and the estimated economic losses amounted to 21.4 trillion KRW. This was a $4.9 \%$ increase from the estimated economic loss of 20.4 trillion KRW in 2015 and double the estimated economic loss of 10.1 trillion KRW in 2002 [9]. It has been estimated that for every 600 near-miss cases of injury, there are 30 cases of property damage, 10 mild injuries, and 1 major injury (the 1-10-30600 accident ratio) $[10,11]$. This suggests that the total costs of injuries would be much greater if unidentified injuries were included.

The Korea Centers for Disease Control and Prevention devel- oped the Korea National Hospital Discharge In-depth Injury Survey (KNHDIS), a national representative survey of injury-related discharges from general hospitals in 2005 to understand the scale of injuries, to identify risk factors, and to provide data supporting prevention policies and intervention strategies. On the basis of this nationally representative injury survey, the total number of injuries severe enough to require admission can be estimated. We investigated trends from 2004 to 2016 and reported updated national injury incidence estimates in Korea since 2004.

\section{MATERIALS AND METHODS}

The KNHIDS, which has been conducted since 2004, collects data on approximately $9 \%$ of discharged cases from medical institutions with 100 or more beds, including hospitals, general hospitals, and secondary community health centers. Hospitals with a single specialty, long-term care hospitals, geriatric hospitals, military hospitals, and rehabilitation hospitals were excluded even if they had 100 or more beds. The KNHDIS applied stratified 2-stage cluster sampling, with individual hospitals as the primary sampling unit and discharged patients in a sampled hospital as the secondary sampling unit. The hospitals were sampled based on clusters of hospitals stratified by geographic location and number of beds. The hospitals were divided into 4 categories according to the number of beds (100-299, 300-499, 500-999, and over 1,000

Table 1. Estimated injury discharge rates, 2004-2016

\begin{tabular}{|c|c|c|c|c|c|c|c|c|c|c|c|c|c|}
\hline Characteristics & 2004 & 2005 & 2006 & 2007 & 2008 & 2009 & 2010 & 2011 & 2012 & 2013 & 2014 & 2015 & 2016 \\
\hline Total (n) & 1,773 & 1,871 & 1,939 & 1,956 & 2,010 & 2,061 & 2,241 & 2,199 & 2,312 & 2,301 & 2,313 & 2,356 & 2,285 \\
\hline \multicolumn{14}{|l|}{ Sex } \\
\hline Male & 2,182 & 2,269 & 2,379 & 2,368 & 2,390 & 2,452 & 2,638 & 2,571 & 2,694 & 2,639 & 2,620 & 2,644 & 2,512 \\
\hline Female & 1,359 & 1,470 & 1,495 & 1,541 & 1,628 & 1,667 & 1,843 & 1,825 & 1,929 & 1,962 & 2,006 & 2,068 & 2,056 \\
\hline \multicolumn{14}{|l|}{ Age (yr) } \\
\hline $0-12$ & 897 & 875 & 818 & 825 & 880 & 832 & 858 & 856 & 882 & 867 & 889 & 822 & 750 \\
\hline $13-18$ & 961 & 1,098 & 1,190 & 1,257 & 1,356 & 1,382 & 1,463 & 1,582 & 1,592 & 1,490 & 1,533 & 1,635 & 1,471 \\
\hline $19-64$ & 1,886 & 1,986 & 2,033 & 2,061 & 2,052 & 2,122 & 2,252 & 2,193 & 2,262 & 2,244 & 2,197 & 2,229 & 2,120 \\
\hline$\geq 65$ & 3,360 & 3,508 & 3,776 & 3,550 & 3,856 & 3,820 & 4,446 & 4,216 & 4,615 & 4,564 & 4,735 & 4,784 & 4,887 \\
\hline \multicolumn{14}{|l|}{ Intent } \\
\hline Unintentional & 1,505 & 1,590 & 1,622 & 1,669 & 1,721 & 1,762 & 1,947 & 1,913 & 2,021 & 2,006 & 2,015 & 2,070 & 2,007 \\
\hline Intentional & 111 & 113 & 114 & 106 & 112 & 106 & 105 & 101 & 92 & 92 & 90 & 82 & 74 \\
\hline Self-harm & 38 & 39 & 43 & 33 & 40 & 39 & 40 & 39 & 37 & 40 & 37 & 37 & 34 \\
\hline Assault & 73 & 74 & 72 & 72 & 71 & 67 & 65 & 62 & 54 & 52 & 53 & 45 & 40 \\
\hline Unknown & 10 & 10 & 15 & 12 & 4 & 4 & 5 & -1 & 6 & 19 & 16 & 17 & 6 \\
\hline \multicolumn{14}{|l|}{ Mechanism } \\
\hline Traffic accident & 669 & 690 & 714 & 746 & 743 & 745 & 772 & 733 & 771 & 729 & 731 & 738 & 670 \\
\hline Falls & 463 & 491 & 518 & 504 & 532 & 558 & 654 & 668 & 703 & 748 & 736 & 783 & 792 \\
\hline Struck by/against & 164 & 173 & 246 & 243 & 242 & 239 & 238 & 263 & 274 & 248 & 251 & 252 & 231 \\
\hline Poisoning & 47 & 47 & 61 & 52 & 55 & 58 & 58 & 55 & 57 & 57 & 59 & 53 & 50 \\
\hline Stabbing & 86 & 141 & 87 & 72 & 77 & 68 & 74 & 67 & 69 & 75 & 62 & 68 & 77 \\
\hline Unknown & 262 & 292 & 189 & 219 & 250 & 257 & 290 & 286 & 301 & 309 & 320 & 319 & 331 \\
\hline
\end{tabular}

Values are presented as number per 100,000 population.

${ }^{1}$ Estimates with relative standard error of less than 5. 
Table 2. Characteristics of injuries by age group

\begin{tabular}{|c|c|c|c|c|c|c|c|c|}
\hline \multirow{2}{*}{ Characteristics } & \multicolumn{2}{|c|}{$0-12$} & \multicolumn{2}{|c|}{$13-18$} & \multicolumn{2}{|c|}{$19-64$} & \multicolumn{2}{|c|}{$\geq 65$} \\
\hline & 2004 & 2016 & 2004 & 2016 & 2004 & 2016 & 2004 & 2016 \\
\hline Total & 67,800 & 40,234 & 34,424 & 48,223 & 557,174 & 682,614 & 122,049 & 298,208 \\
\hline \multicolumn{9}{|l|}{ Intention } \\
\hline Unintentional & 67,072 & 39,934 & 30,613 & 44,737 & 509,023 & 652,438 & 116,313 & 291,179 \\
\hline Self-harm & $75^{3}$ & - & $413^{3}$ & 711 & 15,125 & 12,489 & 2,882 & 4,146 \\
\hline Assault & $578^{3}$ & $280^{3}$ & 3,311 & 2,629 & 29,611 & 16,035 & $1,447^{3}$ & 1,559 \\
\hline Unknown ${ }^{1}$ & $75^{3}$ & $20^{3}$ & $88^{3}$ & $146^{3}$ & 3,414 & 1,652 & 1,408 & 1,324 \\
\hline \multicolumn{9}{|l|}{ Mechanism } \\
\hline Traffic accident & 26,705 & 8,642 & 12,194 & 15,770 & 250,025 & 256,178 & 32,567 & 62,663 \\
\hline Fall & 20,980 & 16,158 & 9,819 & 12,875 & 127,503 & 205,226 & 63,991 & 171,354 \\
\hline Struck by/against & 4,899 & 5,702 & 7,603 & 10,095 & 62,418 & 87,964 & 3,834 & 14,851 \\
\hline Stabbing & 3,209 & 1,372 & 2,514 & 1,789 & 34,270 & 32,109 & 1,505 & 4,315 \\
\hline Fire/heat/flame & 4,662 & $4,269^{3}$ & - & - & - & - & - & - \\
\hline Poisoning & - & - & $194^{3}$ & 667 & 16,883 & 16,573 & 4,821 & 8,087 \\
\hline Unknown ${ }^{1}$ & 7,345 & 4,091 & 2,101 & 7,027 & 66,075 & 84,564 & 15,331 & 36,938 \\
\hline \multicolumn{9}{|l|}{ Source of traffic accident } \\
\hline Subtotal & 26,705 & 8,642 & 12,194 & 15,770 & 250,025 & 256,178 & 32,566 & 62,663 \\
\hline Pedestrian & 14,245 & 3,797 & 2,415 & 2,530 & 31,841 & 30,631 & 8,582 & 16,099 \\
\hline Bicycle & 4,295 & 2,466 & 1,357 & 2,964 & 9,441 & 22,044 & 2,907 & 6,975 \\
\hline Motorcycle & - & - & 4,205 & 5,622 & 24,776 & 24,167 & 5,293 & 10,449 \\
\hline Automobile & 5,672 & 2,160 & 3,103 & 3,817 & 134,558 & 152,443 & 5,612 & 18,079 \\
\hline Unknown ${ }^{1}$ & 2,493 & $219^{3}$ & $1,114^{3}$ & $837^{3}$ & 49,409 & 26,893 & 10,172 & 11,061 \\
\hline \multicolumn{9}{|l|}{ Place of injury } \\
\hline Residence & 16,905 & 8,885 & 3,337 & 2,814 & 58,273 & 65,448 & 34,717 & 78,504 \\
\hline School & 5,255 & 3,331 & 4,611 & 4,345 & - & - & - & - \\
\hline Field/stadium & 3,840 & 2,329 & 3,410 & 6,172 & 15,798 & 20,060 & - & - \\
\hline Roadway & 22,754 & 8,714 & 12,926 & 16,312 & 237,336 & 270,717 & 31,501 & 71,782 \\
\hline Workplace & - & - & - & - & 6,361 & 42,078 & - & - \\
\hline Farm & - & - & - & - & - & - & $1,255^{3}$ & 10,245 \\
\hline Lake.Steam·sea.outdoor & - & - & - & - & - & - & - & 5,816 \\
\hline \multirow[t]{2}{*}{ Unknown 1} & 19,046 & 16,975 & 10,140 & 18,580 & 239,406 & 284,311 & 54,576 & 131,861 \\
\hline & & & & & & & 120,794 & 298,208 \\
\hline \multicolumn{9}{|l|}{ Nature of injury } \\
\hline Fracture & 25,166 & 19,843 & 15,221 & 19,379 & 167,256 & 235,910 & 68,370 & 182,455 \\
\hline Dislocation $^{2}$ & $231^{3}$ & $190^{3}$ & $330^{3}$ & 888 & 4,807 & 8,608 & $1,371^{3}$ & 1,947 \\
\hline Sprain/strain ${ }^{2}$ & 3,290 & 2,197 & 3,756 & 10,974 & 127,891 & 178,330 & 8,892 & 23,992 \\
\hline Internal organ & 12,813 & 4,305 & 6,004 & 4,356 & 101,031 & 77,773 & 21,291 & 35,477 \\
\hline Open wound & 8,734 & 2,330 & 2,715 & 1,523 & 36,204 & 25,589 & 4,830 & 9,036 \\
\hline Traumatic amputation & $937^{3}$ & $108^{3}$ & $72^{3}$ & $73^{3}$ & $10,355^{3}$ & 4,656 & $1,108^{3}$ & $534^{3}$ \\
\hline Vascular injury & $15^{3}$ & $111^{3}$ & - & $140^{3}$ & 2,336 & 2,472 & $145^{3}$ & $527^{3}$ \\
\hline Contusion·superficial injury & 4,638 & 3,177 & 2,138 & 3,738 & 32,447 & 42,885 & 5,796 & 17,277 \\
\hline Crush injury & $1,755^{3}$ & $46^{3}$ & $206^{3}$ & $103^{3}$ & 10,388 & 1,962 & $682^{3}$ & $375^{3}$ \\
\hline Burn & $5,872^{3}$ & $4,607^{3}$ & $613^{3}$ & $879^{3}$ & 14,198 & $19,229^{3}$ & 2,106 & 6,423 \\
\hline Nerve injury & $138^{3}$ & $259^{3}$ & $485^{3}$ & $154^{3}$ & 2,957 & 2,992 & $119^{3}$ & $405^{3}$ \\
\hline Poisoning & 723 & 533 & $227^{3}$ & 668 & 19,033 & 15,414 & 6,749 & 7,870 \\
\hline Others & 4,201 & 2,494 & 3,466 & 5,205 & 36,620 & 66,016 & 4,255 & 11,728 \\
\hline Unknown ${ }^{1}$ & 526 & $34^{3}$ & $338^{3}$ & $143^{3}$ & 4,178 & 778 & $218^{3}$ & $162^{3}$ \\
\hline
\end{tabular}

Values are presented as number of estimated cases.

'Unknown includes unclassified cases.

${ }^{2}$ Dislocations, sprains, and strains were collected without a detailed classification.

${ }^{3}$ Estimates with relative standard error of $25 \%$ or greater. 
beds). Data were collected on patients' age, sex, residence zip code, type of insurance, diagnostic code based on the International Classification of Diseases 10th revision, hospital admission date and discharge date, and injury-related codes such as the mechanism and place of injury occurrence based on the International Classification of External Causes of Injuries version 1.2.

The KNHDIS data captured multiple admissions with no distinction between initial admissions and readmissions. Approximately 230,000 hospitalizations, including multiple admissions, were reviewed every year, from which 30,000 injury cases were identified and examined. The survey was a complex sample survey, and appropriate weights were applied for the estimation. The number of injured cases was estimated using the mid-year estimated population of each year. Linear variance estimation was carried out using the Taylor series, with the SURVEYMEANS procedure provided by SAS version 9.4 (SAS Institute Inc., Cary, NC, USA) [12].

\section{Ethics statements}

The study was exempt from institutional review board approval as the KNHIDS was conducted a part of national injury surveillance system and all analyses in this study were used public-open data.

\section{RESULTS}

In 2016, 170 sample hospitals were selected out of 561 hospitals, and the estimated total number of discharged injury cases was $1,170,713$. This corresponded to $16.5 \%$ of the total of discharges for all causes. The injury discharge rate (per 100,000 population) for males was 1.5 times as high as for females during the surveyed period (1.4 to 1.6). Furthermore, the injury discharge rate showed a linear increase, from 1,505 per 100,000 population in 2004 to 2,007 per 100,000 population in 2016 .

The injury discharge rate increased with age, and this trend was stable over time. However, the difference in the discharge rate between children aged under 12 years old and people aged over 65 years old in each year widened, from 3.7-fold in 2004 (897 vs. 3,360 per 100,000 population) to 6.5 -fold in 2016 (750 vs. 4,887 per 100,000 population). In 2016, patients aged 0-12 displayed the lowest rate (750 per 100,000 population), while the age group of 65 years old and over had a 6.5 times higher value of 4,887. Most injuries were unintentional (93.1\% in $2004,96.4 \%$ in 2016) over this period. The traffic accident rate peaked at 772 people per 100,000 people in 2010, and the discharge rate for injuries caused by traffic accidents reached 669 people per 100,000 in 2016, similar to the rate in 2004. The major causes of unintentional injuries were falls (39.4\%), traffic accidents (33.4\%), and struck by/against injuries (9.7\%) in 2016, whereas the major causes in 2004 were traffic accidents (44.5\%), falls (30.6\%), and struck by/against injuries $(6.8 \%)$. Furthermore, the discharge rate due to assault decreased by $54.8 \%$ from 73 per 100,000 population in 2004 to 40 per 100,000 population in 2016 , while that of self-harm injuries remained mostly unchanged (38 per 100,000 people in 2004, 34 per 100,000 people in 2016) (Table 1).

In the $0-12$ age group, the number of injury discharges decreased by $59.3 \%$ from 67,800 in 2004 to 40,234 in 2016 due to a significant decline of traffic accidents (8,642 in 2016, 26,705 in 2004), which resulted in a sharp drop in roadway injuries.

The number of injuries in the adolescent age group (13-18 years old) and young adults/middle-aged group (19-64 years old) increased by 1.4-fold and 1.2-fold from 2004 to 2016, respectively.

In the elderly group (aged 65 and over), the number of discharged injury cases was 298,208 in 2016, a 1.9-fold increase from 2004. The 2 main causes of injuries were falls (52.4\% in 2004, 57.5\% in $2016)$ and traffic accidents (26.7\% in $2004,21.0 \%$ in 2016) over this period, although the most dramatic increase was found for struck by/against injuries, the rate of which was 3 times higher in 2016 than in 2004.

Injuries from fractures declined in children (under 12 years old), but rose in older age groups; in particular, in the elderly group (aged 65 and over) the number of injuries from fractures increased by more than 3 times, from 68,370 to 182,455 (Table 2).

\section{DISCUSSION}

Injuries are the leading cause of death in young people aged 1030 years old, and play a major role in causing premature death at all ages [13]. To establish sustainable development and to reach the standards of developed countries, the rising trend of the incidence of injuries needs to be reversed through safety promotion initiatives. The total incidence of injuries steadily increased since 2004 in this study. Despite the increased incidence of injuries over the last 10 years, the mortality rate due to injuries has remained stable. This suggests that preventative measures against injuries have not been as effective as measures that address their aftermath. A marked increase in injuries in the elderly has resulted in growing medical costs for chronic diseases, with negative impacts on quality of life; as such, injuries in the elderly have the potential to become a huge obstacle to health promotion in Korean society, which is now in an advanced-age era. On the one hand, there have been improvements in survival and functional recovery after serious injuries due to advances in the treatment of emergencies and in the medical system. On the other hand, close attention needs to be paid in order to reduce the incidence of injuries by reinforcing preventative activities that target what happens before accidents and to yield a synergistic effect with health policies aimed at dealing with what happens subsequent to accidents. Furthermore, according to recent study, regional variations need to be prioritized with individual variations such as age and sex [14].

There are several limitations to this study. First, the KNHDIS captured injuries in patients admitted to hospitals with over 100 beds because the KNHIDS was designed to assess trends at the national level, and detailed information on injuries that were recorded as unknown was not identified. As community and individual risk factors were found to influence the risk of hospitaliza- 
tion for unintentional injuries [14], the surveillance system will be considered as a way to collect data at the community level and on geographical characteristics for developing intervention strategies and implementing prevention programs. Although this was a comparative study over time, we utilized the crude rates in the published statistics of the KNHIDS; thus, future research should use age-adjusted data. Despite these limitations, this survey data allowed us to estimate the number of injury cases on the national scale according to injury mechanism, so the present findings have value for utilization in policy-making to prevent injuries. Further comparative research is needed to identify relevant risk factors to reduce unintentional injuries, drawing upon linkage with various sources of health data such as the Korea National Health and Nutrition Examination Survey.

\section{CONFLICT OF INTEREST}

The authors have no conflicts of interest to declare for this study.

\section{FUNDING}

None.

\section{ACKNOWLEDGEMENTS}

This article is based on a previous article entitled "Epidemiological characteristics of patients admitted for injured inpatients in Korea, 2015" published in "Public Health Weekly Report, 2018; Vol.11, No.11", which is the newsletter of the Korea Centers for Disease Control and Prevention. However, according to subparagraph 306 of the rules and regulations of the publication, its contents can be reused in other publications without copyright issues. Moreover, data from 2016 were used in this article, whereas data from 2015 were used in the previous article, further negating the issue of duplicate submission.

\section{AUTHOR CONTRIBUTIONS}

Conceptualization: YK. Data curation: SOH, BK. Formal analysis: YK, BK. Funding acquisition: None. Methodology: YK, YK. Project administration: YK, SOH, YKL. Visualization: YK, JJ, YKL. Writing-original draft: YK, JJ, OH, BK. Writing-review \& editing: YK, YKL.

\section{ORCID}

Sung Ok Hong: http://orcid.org/0000-0002-0787-4267; Boae Kim: http://orcid.org/0000-0002-2225-5421; Joongho Jo: http://orcid.org/0000-0002-1802-7602; Yunhyung Kwon: http://orcid.org/ 0000-0002-7113-4626; Yeon-Kyeng Lee: http://orcid.org/0000-00020828-455X; Youngtaek Kim: http://orcid.org/0000-0003-0139-7620

\section{REFERENCES}

1. World Health Organization. Manifesto for Safe Communities: safety - a universal concern and responsibility for all [cited 2020 May 9]. Available from: https://www.iadt-dentaltrauma.org/Manifesto\%20for\%20safe\%20communities.pdf.

2. Organization for Economic Cooperation and Development. Health status: causes of mortality [cited 2020 May 9]. Available from: https://stats.oecd.org/index.aspx?queryid $=30115$.

3. International Labour Organization. Fatal occupational injuries per 100,000 workers by sex and migrant status-annual [cited 2020 Jul 13]. Available from: https://www.ilo.org/shinyapps/bulkexplor er38/?lang $=$ en\&segment $=$ indicator\&id $=$ INI_FATL_SEX_MIG_ RT_A.

4. International Transport Forum. Road safety annual report 2018 [cited 2020 Jul 13]. Available from: https://www.itf-oecd.org/sites/ default/files/docs/irtad-road-safety-annual-report-2018_0.pdf.

5. Health Insurance Review \& Assessment Service. 2016 National health insurance statistical yearbook; 2017 [cited 2020 Jul 14]. Available from: https://www.hira.or.kr/bbsDummy.do?pgmid = HIRAA020045010000\&brdScnBltNo $=4 \&$ brdBltNo $=2293 \& p a g$ eIndex $=4$ (Korean).

6. Park K, Han M, Lee U, Jang S, Yu G, Kim Y, et al. Estimation and evaluation of road traffic accident cost. Wonju: Road Traffic Authority; 2015, p. 85 (Korean).

7. Chang T, Kim T, Lee U, Jang S, Jo H, Yu G, et al. Estimation and evaluation of road traffic accident cost. Seoul: Road Traffic Authority; 2014, p. 85 (Korean).

8. Jang Y, Park H, Jo H, Lee U, Yu C, Hwang J, et al. Estimation and evaluation of road traffic accident cost. Seoul: Road Traffic $\mathrm{Au}-$ thority; 2007, p. 63 (Korean).

9. Ministry of Employment and Labor. 2015 Industrial disaster occurrence current status and analysis. Sejong: Ministry of Employment and Labor; 2016, p. 9 (Korean).

10. Lee J, Kim Y, Jeong G, Park H, Kim J, Eun S, et al. Accident statistics database establishment and analysis and research of current status [cited 2019 Jan 24]. Available from: www.snu-dhpm.ac.kr/ $\mathrm{pds} /$ files/안전사고통계DB\%20최종보고서(공단).pdf (Korean).

11. Frank E Bird FE, George L Germain GL. Practical loss control leadership. Loganville: Det Norske Veritas; 1996, p. 21.

12. Lee KO. A study on sampling design and weighting for Korea hospital discharge survey. Seoul: Korea Centers for Diseases Control and Prevention. 2007, p. 29-56 (Korean).

13. Kim J, Kim RH. 2017 Causes of mortality. Daejeon: Statistics Korea: 2018, p. 9 (Korean).

14. Park HS. Investigation of injury-related risk factors affecting Injury hospitalization using multiyear data from the Korea national hospital discharge injury surveillance. Cheongju: Korea Centers for Diseases Control and Prevention. 2017, p. 79-114, 255 (Korean). 